This is an author produced version of a paper published in Geoderma.

This paper has been peer-reviewed and is proof-corrected, but does not include the journal pagination.

Citation for the published paper:

Wetterlind, Johanna; Stenberg, Bo; Söderström, Mats. (2010) Increased sample point density in farm soil mapping by local calibration of visible and near infrared prediction models. Geoderma. Volume: 156, Number: 3-4, pp 152-160.

http://dx.doi.org/10.1016/j.geoderma.2010.02.012.

Access to the published version may require journal subscription.

Published with permission from: Elsevier.

Epsilon Open Archive http://epsilon.slu.se 


\title{
Increased sample point density in farm soil mapping by local calibration of visible and near infrared prediction models
}

\author{
Johanna Wetterlind, Bo Stenberg, Mats Söderström \\ Swedish University of Agricultural Sciences, Department of Soil and Environment, \\ Precision Agriculture and Pedometrics Group, PO Box 234, SE-532 23 Skara, Sweden
}

Published 2010 in Geoderma 156, 152-160

\begin{abstract}
For use as decision support for variable rate applications in precision agriculture, the commonly used sample point density of one sample per hectare is often not enough. However, increasing the sampling density using laboratory analyses is too expensive for farmers to implement. It is therefore important to find methods for rationalisation. To this end, farm-scale visible and near infrared reflection (vis-NIR) calibrations were established on two farms in southern Sweden (Hacksta and Sjöstorp) for soil texture, soil organic matter, total $\mathrm{N}, \mathrm{pH}$ and plant-available $\mathrm{P}, \mathrm{K}$ and $\mathrm{Mg}$. By keeping the laboratory analyses to a minimum to be used for vis-NIR calibrations and only collecting vis-NIR spectra from the vast majority of the samples, the sampling density could be increased without significantly increasing the cost. In this study 25 samples were used in the calibrations. Six different calibration sample selection methods were compared, selected from three different datasets originating from a larger context aiming at covering soil variations. Using only 25 calibration samples resulted in good predictions for clay at both farms, $\mathrm{r}^{2}$ values of 0.81 and 0.89 and RMSEP values of 3.6 and $3.9 \%$. Sand, soil organic matter and total nitrogen were well predicted at Hacksta $\left(\mathrm{r}^{2}=0.87,0.90\right.$ and 0.89 and RMSEP=3.0, 0.28 and $0.018 \%$ respectively) but 25 samples proved to be too few at the geologically divided farm Sjöstorp. For predicting $\mathrm{pH}$ and plant-available $\mathrm{P}, \mathrm{K}$ and $\mathrm{Mg}$, more than 25 calibration samples were needed at both farms, although with $75 \%$ of all reference samples (92 and 94 at Hacksta and Sjöstorp respectively) in the calibration these parameters also showed potential for building useful NIR calibrations (RPD values between 2.3 and 2.8 except for the predictions for $\mathrm{pH}$ at one of the farms resulting in an RPD value of 1.6). However, predictions for silt content were less reliable and the small number of calibration samples was not the limiting factor in this case. The promising results are encouraging for further development of costeffective high resolution farm soil maps using NIR spectroscopy.
\end{abstract}

Keywords: Diffuse reflectance spectroscopy, Plant-available P, K and Mg, Soil pH, Precision agriculture, Clay, Soil organic matter

\section{Introduction}

Farm soil mapping is the main source of information to farmers on the plant nutrient status of their soil and provides basic data for decision-making on e.g. fertilisation and liming. In contrast to the more stable parameters such as soil texture and to some extent soil organic matter (SOM) content, the amount of plant nutrients changes due to farming practices and thus farm soil maps need to be renewed regularly. The conventional soil sampling density in Sweden and many other countries is one sample per hectare. Soil texture and SOM content are often analysed on every second or third sample or not at all. However, soil properties can vary extensively within fields (e.g. Delin and Söderström, 2003) and for reliable decision support in precision agriculture for variable rate applications, this density would not be sufficient. Soil sampling and conventional laboratory analyses are timeconsuming and costly. Increasing the sampling density would simultaneously increase the cost and would thus become too expensive for farmers to implement. It is therefore important to find methods for rationalisation.

Near infrared reflectance (NIR) spectroscopy is frequently put forward as such a technique (van Vuuren et al., 2006; Viscarra Rossel et al., 2006; Wetterlind et al., 2008b; Zornoza et al., 2008). NIR is a fast nondestructive technique that only requires limited sample preparation. In addition, several properties can be determined from a single scan. A number of studies have shown the potential of NIR to predict soil texture (Chang et al., 2001; Shepherd and Walsh, 2002; Islam et al., 2003; Moron and Cozzolino, 2003; Viscarra Rossel et al., 2006) and SOM content (Dalal and Henry, 1986; Morra et al., 1991; Sudduth and Hummel, 1991; Reeves et al., 1999; Chang et al., 2001; Udelhoven et al., 2003; Wetterlind et al., 2008a). Particle size and SOM content could be considered primary properties in relation to NIR, since NIR spectra are directly influenced by combinations and overtones of funda- 
mental vibrations for organic functional groups, particlesize and surface properties (Ben-Dor and Banin, 1995b; Chang et al., 2001). Other farm soil mapping properties such as plant nutrients and $\mathrm{pH}$ may in some situations be predicted with NIR spectroscopy due to correlations to more spectrally active properties (BenDor and Banin, 1995a; Chang et al., 2001). Promising results have for example been reported for prediction of e.g. pH (Malley et al., 1999; Dunn et al., 2002; van Vuuren et al., 2006), various forms of phosphorus (Malley et al., 1999; Daniel et al., 2003; Bogrekci and Lee, 2005; Maleki et al., 2006), potassium (Chang et al., 2001; van Vuuren et al., 2006; Zornoza et al., 2008) and magnesium (Malley et al., 2000; Shepherd and Walsh, 2002; van Groenigen et al., 2003; Maleki et al., 2006).

In the majority of the field-scale NIR calibrations presented in earlier studies, a substantial amount of the soil samples have been used in the calibrations, resulting in laboratory analyses on more than one sample per ha (e.g. McCarty and Reeves, 2006; Viscarra Rossel et al., 2006; He et al., 2007). However, if the vast majority of the samples are measured for their NIR spectra only and the number of reference samples with laboratory analyses is kept to a minimum for NIR calibrations and prediction of those with NIR-data only, the sampling density can be increased without significantly increasing costs. Wetterlindet al. (2008b) presented promising results from such a strategy for clay and SOM content from one of the farms included in the present study. With few calibration samples, it is crucial to cover as muchof the variation as possible. Wetterlindet al. (2008b) selected calibration samples from the two different sampling strategies according to their $\mathrm{EC}_{\mathrm{a}}$ or reflectance values from a satellite image. Another possible way,as proposed by e.g. McCarty and Reeves (2006), is to select the most spectrally diverse samples for calibration. Stenberg et al. (1995) presented a method for selecting a small subset of samples while retaining a maximum of the original variation in important soil properties using principal component analysis of the NIR spectra.

The aims of this study were to: a) further investigate the feasibility of establishing farm-scale NIR calibration models for some of the most common farm soil mapping properties in Sweden (soil texture, SOM, total $\mathrm{C}$, total nitrogen, $\mathrm{pH}$ and ammonium acetate lactate (AL)-extractable $\mathrm{P}, \mathrm{K}$ and $\mathrm{Mg}$ ) with only 25 calibration samples in order to increase sampling density without increasing the cost; b) compare the prediction power of six calibration sample sets selected from three different sampling selection strategies. The sampling selection strategies and the calibration sample selection methods were aiming at covering as much of the soil variation as possible within all samples and within the calibration samples. For comparison, a sampling strategy and calibration sampling selection method simply using a regular grid was included.

\section{Materials and methods}

\section{Sites and experimental design}

The farms studied were Hacksta $\left(59^{\circ} 33^{\prime} \mathrm{N}, 17^{\circ} 02^{\prime} \mathrm{E}\right)$, about $70 \mathrm{~km}$ north-west of Stockholm, and Sjöstorp $\left(55^{\circ} 41^{\prime} \mathrm{N}, 13^{\circ} 19^{\prime} \mathrm{E}\right)$, about $20 \mathrm{~km}$ north-east of Malmö (Fig. 1). Crop rotations at both farms were dominated by cereals, and no farmyard manure had been applied for many years. The studied area at Hacksta covered five adjacent fields with a total area of 97 ha. The soils on this farm are dominated by glacial and postglacial clay with elements of sandy till (Möller, 1985), and vary from loam to clay with only small topographical differences. At Sjöstorp, 10 fields covering an area of 78 ha were studied. A clear borderline between two different types of glacial till soil divides this farm into an 18 ha north-eastern part and a 60 ha south-western part. The former consists of sandy till, while the latter consists of clay till with elements of chalk, changing to glacial clay close to the borderline.

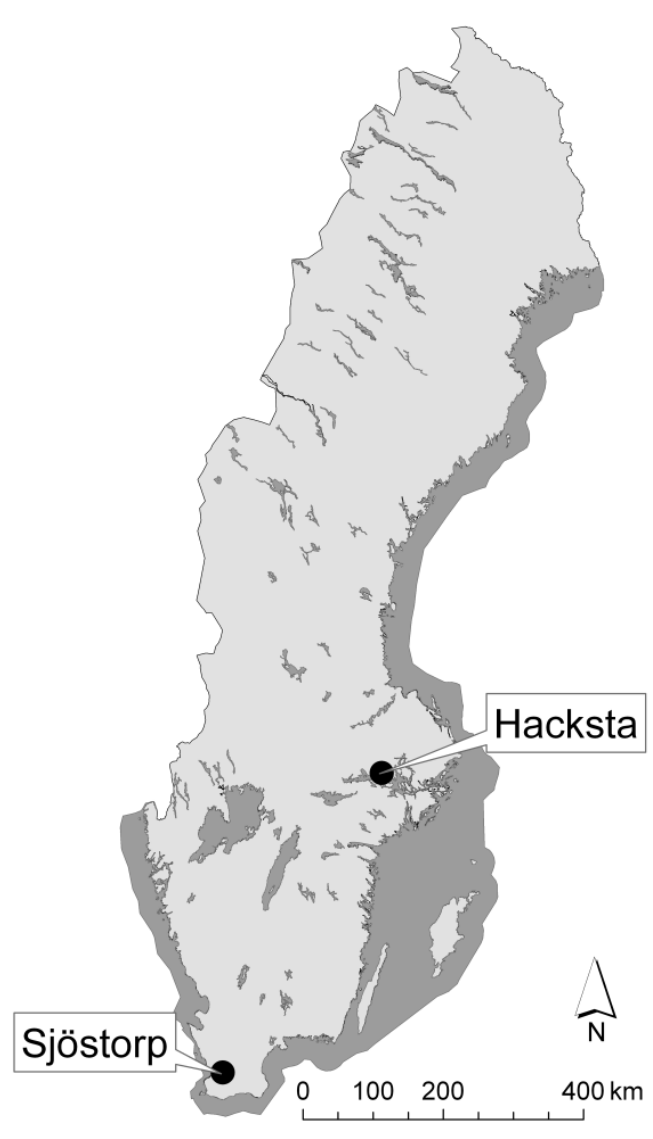

Fig 1 . The location of the two farms. 
The soil samples in this study were taken according to three strategies for selecting soil sample locations to capture the spatial soil variation at the farm. The three datasets were sampled according to: a), EC $_{a}$ values (EC), b) reflectance values from a satellite image (SAT) or c) for comparison, a regular grid (REG). The samples were collected at a density of approximately 1.5 samples per ha resulting in about 130 samples each in the REG, EC and SAT strategies at Sjöstorp and about 150 samples each at Hacksta. The soil samples (0-20 cm depth) were taken in autumn 2005 at Hacksta and autumn 2006 at Sjöstorp. Twenty sub-samples within a radius of about $6 \mathrm{~m}$ were bulked to form a composite sample. The $\mathrm{EC}_{\mathrm{a}}$ values were recorded in spring 2005 at Hacksta and in spring 2006 at Sjöstorp using EM38 (Geonics Ltd., Mississauga, Ontario, Canada). The measurements were carried out at intervals of about $10 \mathrm{~m}$ at Hacksta and $24 \mathrm{~m}$ at Sjöstorp along transects parallel to the tramlines. The satellite data used at Hacksta was the 1580-1750 nm band from a $10 \mathrm{~m}$ resolution SPOT 5 scene recorded on 21 March 2003. At Sjöstorp the 750-900 nm band from a $25 \mathrm{~m}$ resolutionLandsat7 scenerecordedon23 March2003 wasused. The satellite data were obtained from the Swedish Land Survey. The strategy for targeted sampling adopted here was a directed sampling that through an iterative procedure selects samples from an exhaustive data set $\left(E_{a}\right.$ values or reflectance values from a satellite image in this case). The ultimate goal of that selection procedure was to be able to produce a map of the variable which should be as similar as possible to a mapproduced using all data in the exhaustivedata set. An automated method was used, described by Olsson and Söderström (2003) that minimizes the differences between these maps. In addition, it fulfils some other criteria, such as fairly even spatial coverage of sites and sampling no closer than $15 \mathrm{~m}$ to field borders and $12 \mathrm{~m}$ to locations already selected. This procedure of stratified, directed sampling includes the following steps: creation of a map of the ancillary data, subdivision of the fields into 1.5 ha cells and an iterative process inserting sampling sites successively in order to reach the desired number of samples or sampling density.

\section{Soil analyzes}

Before all analyses, the soil was air-dried and crushed to pass a $2 \mathrm{~mm}$ sieve. Vis-NIR spectra were collected on all samples from the REG, EC and SAT sampling strategies using a FieldSpec Pro FR scanning instrument (Analytical Spectral Devices Inc., Boulder, CO, USA). The instrument was equipped with a bare optic fibre. The fibre was assembled together with a $20 \mathrm{~W}$ Al-coated halogen tungsten light source $7 \mathrm{~cm}$ over the soil sample, resulting in a field of view of $\sim 7.5 \mathrm{~cm}^{2}$. Reflectance spectra were recorded in relation to an external white reference (Spectralon). Each spectrum comprised 100 averaged sub-spectra from a rotating sample, covering a total sample area of about $50 \mathrm{~cm}^{2}$. Reflectance spectra from two sub-samples of each soil sample were recorded. The spectral range was 350$2500 \mathrm{~nm}$ at $1.4-2.0 \mathrm{~nm}$ intervals with a resolution of $3-10 \mathrm{~nm}$. The vis-NIR region defined as $430-2500 \mathrm{~nm}$ was used. The shortest wavelengths were excluded due to excessive noise.

Soil samples to be used in the vis-NIR calibrations were selected for conventional laboratory analyses for soil texture, SOM content, total C, total $\mathrm{N}, \mathrm{pH}$ and $\mathrm{P}-$, $\mathrm{K}-$ and Mg-AL. Soil texture was divided into clay $(<$ $0.002 \mathrm{~mm})$, silt $(0.002-0.063 \mathrm{~mm})$ and sand $(0.063-2$ $\mathrm{mm}$ ). Clay content was analysed using a sedimentation method modified from Gee and Bauder (1986), the sand fraction was determined by sieving and the silt fraction was determined by difference. Total $\mathrm{C}$ was analysed through dry combustion at $900{ }^{\circ} \mathrm{C}$ with a vario MAX analyser (Elementar, Analysensysteme GmbH, Hanau, Germany) and SOM was analysed by loss on ignition (LI) corrected for loss of structural water from clay minerals (Ekström, 1927) according to: $\mathrm{SOM}=\mathrm{LI}-0.46-0.047 \times$ clay content $(\%)$. Total $\mathrm{N}$ was analysed through dry combustion at $1250{ }^{\circ} \mathrm{C}$ with a LECO ${ }^{\circledR}$ FP-428 analyser (LECO Corporation, St. Joseph, MI, USA) and $\mathrm{pH}$ was measured in deionised water at a soil:water volume ratio of 1:5 (SS-ISO 10 390). P-AL, K-AL, Ca-AL and Mg-AL were analysed according to Egnér et al. (1960) (SS-02 83 10).

\section{Calibration sample selection}

From each of the three sample sets REG, EC and SAT, 25 calibration samples were selected in two different ways resulting in six different calibration sets (Table 1). One method of selection was applied on all three sample sets. With this method the 25 samples from each set were selected according to their vis-NIR spectra denoted as subscript associated to the original sample set $\left(\mathrm{REG}_{\mathrm{NIR}}, \mathrm{EC}_{\mathrm{NIR}}\right.$ and $\left.\mathrm{SAT}_{\mathrm{NIR}}\right)$ to cover as much of the spectral variation between samples as possible, manifested by extremes in the first five principal components in a principal component analysis (PCA). Thus for each of the five principal components, 2-3 samples with the highest positive scores and 2-3 samples with the highest negative scores were chosen, with the larger number of samples chosen in the first components. The other methods of selecting calibration samples differed with sample set. In the EC and SAT strategies, 25 samples were selected according to their $\mathrm{EC}_{\mathrm{a}}$ or reflectance values, respectively, $\left(\mathrm{EC}_{\mathrm{EC}}\right.$ and $\mathrm{SAT}_{\mathrm{SAT}}$ ) using the same targeted sampling strategy as described earlier. In practice this means that the 25 first samples of the original sample sets, supposed to represent as much of the variation in $\mathrm{EC}_{\mathrm{a}}$ or reflectance values as possible, were selected for calibrations. In 


\begin{tabular}{|c|c|c|}
\hline Label & $\begin{array}{l}\text { Soil sample distribution } \\
\text { strategy }\end{array}$ & $\begin{array}{l}\text { Calibration sample } \\
\text { selection strategy }\end{array}$ \\
\hline $\mathrm{REG}_{\mathrm{REG}}$ & according to a regular grid & $\begin{array}{l}\text { according to a regular } \\
\text { grid }\end{array}$ \\
\hline $\mathrm{REG}_{\mathrm{NIR}}$ & according to a regular grid & $\begin{array}{l}\text { according to NIR } \\
\text { spectra }\end{array}$ \\
\hline $\mathrm{EC}_{\mathrm{EC}}$ & $\begin{array}{l}\text { targeted according to } \mathrm{EC}_{\mathrm{a}} \\
\text { values }\end{array}$ & according to $\mathrm{EC}_{\mathrm{a}}$ values \\
\hline $\mathrm{EC}_{\mathrm{NIR}}$ & $\begin{array}{l}\text { targeted according to } \mathrm{EC}_{\mathrm{a}} \\
\text { values }\end{array}$ & $\begin{array}{l}\text { according to NIR } \\
\text { spectra }\end{array}$ \\
\hline $\mathrm{SAT}_{\mathrm{SAT}}$ & $\begin{array}{l}\text { targeted according to a } \\
\text { satellite image }\end{array}$ & $\begin{array}{l}\text { according to a satellite } \\
\text { image }\end{array}$ \\
\hline $\mathrm{SAT}_{\mathrm{NIR}}$ & $\begin{array}{l}\text { targeted according to a } \\
\text { satellite image }\end{array}$ & $\begin{array}{l}\text { according to NIR } \\
\text { spectra }\end{array}$ \\
\hline
\end{tabular}

addition to the calibration selection methods designed to cover as much of the soil variation as possible, 25 samples from the REG strategy were selected for comparison simply by selecting approximately every fifth sample distributed in a coarser regular grid $\left(R G_{\mathrm{REG}}\right)$. Some of the samples co-insided and were included in more than one calibration set, resulting in 122 soil samples with reference analyses at Hacksta and 125 at Sjöstorp.

\section{NIR calibrations}

The recorded NIR spectra were transformed to absorbance by $\log \left(\right.$ reflectance $\left.^{-1}\right)$ and the two replicates were averaged. To enhance weak signals, reduce noise and reduce light scatter effects influencing the baseline, each vis-NIR spectrum was transformed and smoothed by first-order, 17-point (Hacksta) or 25-point (Sjöstorp) Savitzky-Golay derivative (Savitzky and Golay, 1964). At each farm, vis-NIR spectra were calibrated to the soil properties by partial least squares (PLS) regression (Martens and Naes, 1989) using the six different calibration datasets. Cross-validation through a leave-one-out procedure was used to determine the optimum number of PLS factors included in the calibrations.

In the absence of a separate validation sample set, comparisons between the different strategies were made in two steps to allow for as large and diverse validation sets as possible. In step one, the calibration sample selection methods were compared within each spatial sample distribution strategy, allowing samples from the remaining two strategies to be used in the validation (Fig. 2). Thus, the calibration models based on $R_{E G_{R E G}}$ and $R_{E G}$ NIR were validated using samples from the EC and SAT calibration sample sets, $\mathrm{EC}_{\mathrm{EC}}$ and $\mathrm{EC}_{\mathrm{NIR}}$ using REG and SAT calibration data, etc. The calibration resulting in the lowest RMSEP values of each pair $\left(\mathrm{EC}_{\mathrm{EC}}-\mathrm{EC}_{\mathrm{NIR}}, \mathrm{REG}_{\mathrm{REG}}-\mathrm{REG}_{\mathrm{NIR}}\right.$ and $\mathrm{SAT}_{\mathrm{SAT}}-\mathrm{SAT}_{\mathrm{NIR}}$ ) was considered the better of the

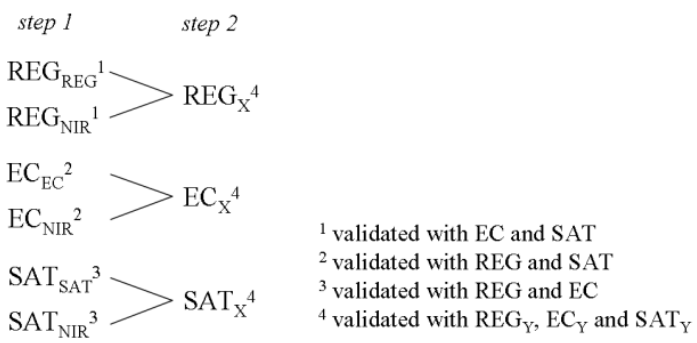

Fig. 2. Schematic diagram of the two steps in the comparison between the different sample strategies. $\mathrm{X}$ is the better of the two selection methods compared in step 1 and $\mathrm{Y}$.

is the other selection method.two. The calibration sample selection method that gave the best results in the majority of the comparisons at each farm was considered best and selected for step two. In step two, these sample selection methods were used for comparing the three sampling strategies (REG, EC and SAT). In this step the sample sets remaining from step one were used as a common validation set (Fig. 2).

In addition, calibration models with all reference samples were made for all soil parameters at each farm by randomly selecting $75 \%$ of the reference samples for calibration and the remaining $25 \%$ for validation. Comparing the results from these models with the calibration models using only 25 calibration samples can provide information on the stability and potential for farm-scale predictions of the different soil properties.

All validations were evaluated by the $r^{2}$ value of the relationship between the NIR estimate of the soil property and the reference measurement, the root mean squared error of prediction (RMSEP) and the ratio of performance to deviation (RPD) (standard deviation (s.d.) divided by RMSEP) (Williams, 1987). All NIRdata analyses and statistics were performed using Unscrambler 9.7 (CAMO PROCESS AS, Oslo, Norway).

\section{Results}

The range in the different soil parameters for the laboratory analyses on all reference samples at Hacksta and Sjöstorp is presented in Table 2 . In general, there were only small differences between the calibration sets. However, for example at Sjöstorp, $\mathrm{SAT}_{\mathrm{SAT}}$ failed to

include the highest values in several parameters. Hacksta soils were considerably finer textured than Sjöstorp, where the sand fraction was generally larger. At Sjöstorp, the highest clay and SOM contents were found in an area close to the borderline between the clay till and the sandy till in the area with glacial clay, and many of the soil parameters had high values in this area. Correlations between the soil parameters at both farms are presented in Tables 3 and 4. 
Table 2. Range and mean for the laboratory analyses on all reference samples and on the six calibration sample sets (not mean) at Hacksta and Sjöstorp

\begin{tabular}{|c|c|c|c|c|c|c|c|c|}
\hline & \multicolumn{2}{|c|}{ All ref. ${ }^{1}$} & \multirow{2}{*}{$\begin{array}{l}\mathrm{REG}_{\mathrm{REG}} \\
\text { range }\end{array}$} & \multirow{2}{*}{$\begin{array}{l}\mathrm{REG}_{\mathrm{NIR}} \\
\text { range }\end{array}$} & \multirow{2}{*}{$\begin{array}{l}\mathrm{EC}_{\mathrm{EC}} \\
\text { range }\end{array}$} & \multirow{2}{*}{$\begin{array}{l}\mathrm{EC}_{\mathrm{NIR}} \\
\text { range }\end{array}$} & \multirow{2}{*}{$\begin{array}{l}\mathrm{SAT}_{\mathrm{SAT}} \\
\text { range }\end{array}$} & \multirow{2}{*}{$\begin{array}{l}\mathrm{SAT}_{\mathrm{NIR}} \\
\text { range }\end{array}$} \\
\hline & mean & range & & & & & & \\
\hline \multicolumn{9}{|l|}{ Hacksta } \\
\hline Clay (\%) & 47 & $22-66$ & $30-59$ & $31-66$ & $22-62$ & $31-60$ & $32-62$ & $29-66$ \\
\hline Silt (\%) & 39 & $25-58$ & $28-50$ & $25-48$ & $28-49$ & $26-58$ & $30-51$ & $25-47$ \\
\hline Sand (\%) & 14 & $2-47$ & 3-34 & 3-34 & $2-47$ & $2-28$ & $3-30$ & $3-38$ \\
\hline SOM (\%) & 4.0 & $1.5-8.0$ & $1.8-6.7$ & $1.5-6.1$ & $1.8-8.0$ & $1.5-6.9$ & $1.9-7.5$ & $1.8-7.5$ \\
\hline tot C (\%) & 2.3 & 1.3-4.1 & $1.5-3.7$ & 1.4-3.0 & 1.4-4.1 & 1.4-3.0 & $1.3-3.5$ & $1.4-3.5$ \\
\hline tot N (\%) & 0.23 & $0.13-0.55$ & $0.14-0.55$ & $0.14-0.32$ & $0.14-0.41$ & $0.14-0.32$ & $0.13-0.33$ & $0.13-0.34$ \\
\hline $\mathrm{pH}$ & 6.6 & $5.9-7.6$ & $6.4-7.0$ & $6.2-7.5$ & $6.4-6.8$ & $6.2-6.9$ & $6.0-7.0$ & $5.9-7.6$ \\
\hline P-AL (mg $100 \mathrm{~g}^{-1}$ ) & 9 & $2-39$ & $4-18$ & $3-22$ & $2-21$ & $2-23$ & 4-19 & 4-39 \\
\hline $\mathrm{K}-\mathrm{AL}\left(\mathrm{mg} 100 \mathrm{~g}^{-1}\right)$ & 21 & $12-39$ & $15-39$ & $13-39$ & $12-30$ & $16-33$ & $12-39$ & $14-39$ \\
\hline Mg-AL (mg $\left.100 \mathrm{~g}^{-1}\right)$ & 33 & $11-65$ & $19-64$ & $12-65$ & $14-56$ & $12-57$ & $15-62$ & $11-56$ \\
\hline \multicolumn{9}{|l|}{ Sjöstorp } \\
\hline Clay (\%) & 25 & $12-52$ & $12-52$ & $13-52$ & $12-48$ & $12-49$ & $12-43$ & $14-51$ \\
\hline Silt (\%) & 28 & $13-38$ & $25-37$ & $22-37$ & $19-38$ & 24-35 & $13-34$ & $13-38$ \\
\hline Sand (\%) & 46 & $12-73$ & $12-62$ & $12-65$ & $14-65$ & $18-63$ & $27-73$ & $18-73$ \\
\hline SOM (\%) & 3.2 & $2.0-7.4$ & $2.0-7.0$ & $2.0-7.4$ & $2.2-6.6$ & $2.5-7.0$ & $2.0-4.3$ & $2.0-4.7$ \\
\hline tot C (\%) & 1.8 & 1.2-3.9 & $1.3-3.4$ & 1.3-3.9 & 1.3-3.2 & 1.3-3.9 & $1.2-2.3$ & $1.4-3.4$ \\
\hline tot N (\%) & 0.18 & $0.12-0.39$ & $0.12-0.33$ & $0.12-0.39$ & $0.12-0.34$ & 0.14-0.39 & $0.12-0.23$ & $0.13-0.24$ \\
\hline $\mathrm{pH}$ & 6.9 & $6.1-7.8$ & $6.1-7.8$ & $6.4-7.7$ & $6.3-7.8$ & $6.2-7.6$ & $6.3-7.7$ & $6.4-7.7$ \\
\hline P-AL (mg $100 \mathrm{~g}^{-1}$ ) & 10 & 4-31 & $4-24$ & 4-31 & $5-24$ & $4-31$ & $5-30$ & $4-17$ \\
\hline K-AL (mg $100 \mathrm{~g}^{-1}$ ) & 17 & $7-38$ & $7-38$ & $7-28$ & $10-28$ & $7-32$ & $11-25$ & $11-32$ \\
\hline Mg-AL (mg $\left.100 \mathrm{~g}^{-1}\right)$ & 12 & $3-44$ & $5-44$ & 4-44 & $4-25$ & $5-44$ & $5-23$ & $5-33$ \\
\hline
\end{tabular}

${ }^{1}$ All reference samples, 122 at Hacksta and 125 at Sjöstorp

Table 3. Correlation matrix of laboratory analyses for all reference samples at Hacksta

\begin{tabular}{|c|c|c|c|c|c|c|c|c|c|c|}
\hline & Clay & Silt & Sand & SOM & tot $\mathrm{C}$ & tot $\mathrm{N}$ & $\mathrm{pH}$ & P-AL & $\mathrm{K}-\mathrm{AL}$ & Mg-AL \\
\hline Clay & 1 & & & & & & & & & \\
\hline Silt & -0.26 & & & & & & & & & \\
\hline Sand & -0.76 & -0.43 & 1 & & & & & & & \\
\hline SOM & 0.36 & 0.50 & -0.68 & 1 & & & & & & \\
\hline tot $\mathrm{C}$ & 0.41 & 0.32 & -0.61 & 0.92 & 1 & & & & & \\
\hline tot $\mathrm{N}$ & 0.43 & 0.32 & -0.62 & 0.87 & 0.96 & 1 & & & & \\
\hline $\mathrm{pH}$ & 0.14 & -0.38 & 0.13 & -0.30 & -0.25 & -0.22 & 1 & & & \\
\hline P-AL & -0.41 & -0.36 & 0.62 & -0.33 & -0.27 & -0.34 & 0.28 & 1 & & \\
\hline K-AL & 0.19 & -0.32 & 0.04 & -0.02 & 0.08 & 0.06 & 0.38 & 0.39 & 1 & \\
\hline Mg-AL & 0.45 & 0.45 & -0.72 & 0.68 & 0.62 & 0.62 & -0.11 & -0.48 & -0.12 & 1 \\
\hline
\end{tabular}

Table 4. Correlation matrix of laboratory analyses for all reference samples at Sjöstorp

\begin{tabular}{|c|c|c|c|c|c|c|c|c|c|c|}
\hline & Clay & Silt & Sand & SOM & tot C & tot $\mathrm{N}$ & $\mathrm{pH}$ & P-AL & K-AL & Mg-AL \\
\hline Clay & 1 & & & & & & & & & \\
\hline Silt & 0.42 & 1 & & & & & & & & \\
\hline Sand & -0.95 & -0.68 & 1 & & & & & & & \\
\hline SOM & 0.39 & 0.35 & -0.44 & 1 & & & & & & \\
\hline tot $\mathrm{C}$ & 0.46 & 0.24 & -0.46 & 0.77 & 1 & & & & & \\
\hline tot $\mathrm{N}$ & 0.33 & 0.25 & -0.35 & 0.91 & 0.88 & 1 & & & & \\
\hline $\mathrm{pH}$ & 0.60 & 0.24 & -0.56 & -0.07 & 0.02 & -0.12 & 1 & & & \\
\hline P-AL & -0.18 & -0.26 & 0.24 & -0.04 & 0.07 & 0.06 & 0.06 & 1 & & \\
\hline K-AL & 0.64 & 0.27 & -0.61 & 0.27 & 0.41 & 0.26 & 0.43 & 0.25 & 1 & \\
\hline Mg-AL & 0.83 & 0.41 & -0.81 & 0.27 & 0.55 & 0.27 & 0.52 & -0.21 & 0.64 & 1 \\
\hline
\end{tabular}


Step one, comparing calibration sample selections

In the pair-wise comparison between selecting calibration samples according to vis-NIR spectra or according to a regular grid, $\mathrm{EC}_{\mathrm{a}}$ values or a satellite image (Fig. 2), no general conclusions could be drawn regarding the best method. At Sjöstorp, the selection according to vis-NIR resulted in the best predictions in the majority of the calibrations, whereas the opposite was true at Hacksta (predictions not shown). Therefore, $\mathrm{REG}_{\mathrm{REG}}, \mathrm{SAT}_{\mathrm{SAT}}$ and $\mathrm{EC}_{\mathrm{EC}}$ at Hacksta and $\mathrm{REG}_{\mathrm{NIR}}$, $\mathrm{SAT}_{\mathrm{NIR}}$ and $\mathrm{EC}_{\mathrm{NIR}}$ at Sjöstorp were chosen for further comparison in step two.

\section{Step two, comparing sampling strategy}

Prediction results comparing the different sampling strategies at the two farms are presented in Table 5. At Hacksta, the $\mathrm{SAT}_{\mathrm{SAT}}$ strategy performed better than the other two, with lower RMSEP values and higher $r^{2}$ values for almost all parameters, but the differences were generally quite small. At Sjöstorp, on the other hand, no sampling strategy was markedly better than the other. In general, predictions were somewhat better at Hacksta than at Sjöstorp. At Hacksta the best predictions were those of SOM, total C, total N and sand. At Sjöstorp, clay content was best predicted whereas the predictions of SOM and total C resulted in $\mathrm{r}^{2}$ values of only 0.46 and 0.41 at best, respectively, compared with 0.89 and 0.87 at Hacksta, and in RPD values of only half that at Hacksta. Silt, $\mathrm{pH}$ and the AL-extractable plant nutrients resulted in less reliable predictions, with sometimes quite large differences between the three methods.

\section{All reference samples}

Predictions by the calibration models made on all reference samples at both farms are presented in Table 6. At both farms, the majority of the calibrations, resulted in $r^{2}$ values between 0.73 and 0.95 and RPD values between 2.0 and 3.7. Predictions for silt resulted in RMSEP values comparable to those for both clay and sand, but with $\mathrm{r}^{2}$ values of about 0.63 at Sjöstorp. At Hacksta, the resulting $\mathrm{r}^{2}$ and RPD values for $\mathrm{pH}$ were rather low compared with those at Sjöstorp, despite similar RMSEP values.

Table 5. Prediction results from VisNIR calibration models at Hacksta and Sjöstorp in step two, comparing the three different sample distribution strategies

\begin{tabular}{|c|c|c|c|c|c|c|c|c|c|c|c|c|}
\hline & \multicolumn{4}{|c|}{$\mathrm{REG}^{1}$} & \multicolumn{4}{|c|}{$\mathrm{EC}^{2}$} & \multicolumn{4}{|c|}{ SAT $^{3}$} \\
\hline & $\mathrm{PC}^{4}$ & $\mathrm{R}^{2}$ & RMSEP & RPD & $\mathrm{PC}$ & $\mathrm{R}^{2}$ & RMSEP & RPD & $\mathrm{PC}$ & $\mathrm{R}^{2}$ & RMSEP & RPD \\
\hline \multicolumn{13}{|l|}{ Hacksta } \\
\hline Clay (\%) & 4 & 0.72 & 4.4 & 1.9 & 8 & 0.77 & 4.0 & 2.1 & 5 & 0.76 & 4.1 & 2.0 \\
\hline Silt (\%) & 5 & 0.58 & 4.2 & 1.6 & 3 & 0.31 & 5.4 & 1.2 & 5 & 0.61 & 4.1 & 1.6 \\
\hline Sand (\%) & 10 & 0.81 & 3.6 & 2.3 & 9 & 0.84 & 3.3 & 2.6 & 10 & 0.87 & 3.0 & 2.8 \\
\hline $\mathrm{pH}$ & 4 & 0.28 & 0.23 & 1.2 & 8 & 0.39 & 0.21 & 1.3 & 9 & 0.50 & 0.19 & 1.4 \\
\hline $\operatorname{SOM}(\%)$ & 8 & 0.88 & 0.48 & 3.0 & 6 & 0.81 & 0.62 & 2.3 & 11 & 0.89 & 0.47 & 3.0 \\
\hline tot C (\%) & 8 & 0.85 & 0.20 & 2.6 & 6 & 0.86 & 0.19 & 2.7 & 10 & 0.87 & 0.19 & 2.8 \\
\hline tot N (\%) & 2 & 0.45 & 0.04 & 1.4 & 6 & 0.82 & 0.023 & 2.4 & 10 & 0.89 & 0.018 & 3.0 \\
\hline P-AL (mg 100g ${ }^{-1}$ ) & 6 & 0.51 & 4.9 & 1.4 & 2 & 0.33 & 5.8 & 1.2 & 6 & 0.66 & 4.1 & 1.7 \\
\hline $\mathrm{K}-\mathrm{AL}\left(\mathrm{mg} 100 \mathrm{~g}^{-1}\right)$ & 7 & 0.68 & 2.6 & 1.8 & 6 & 0.58 & 3.0 & 1.6 & 10 & 0.48 & 3.3 & 1.4 \\
\hline Mg-AL (mg $\left.100 g^{-1}\right)$ & 2 & 0.67 & 7.3 & 1.8 & 4 & 0.77 & 6.2 & 2.1 & 5 & 0.75 & 6.4 & 2.0 \\
\hline \multicolumn{13}{|l|}{ Sjöstorp } \\
\hline Clay (\%) & 4 & 0.80 & 4.1 & 2.3 & 5 & 0.87 & 3.3 & 2.8 & 2 & 0.79 & 4.2 & 2.2 \\
\hline Silt (\%) & 4 & 0 & 3.8 & 1.0 & 1 & 0 & 3.9 & 1.0 & 1 & 0 & 3.7 & 1.0 \\
\hline Sand (\%) & 4 & 0.67 & 6.5 & 1.8 & 4 & 0.74 & 5.8 & 2.0 & 3 & 0.54 & 7.7 & 1.5 \\
\hline $\mathrm{pH}$ & 1 & 0.64 & 0.28 & 1.7 & 3 & 0.52 & 0.32 & 1.5 & 1 & 0.59 & 0.30 & 1.6 \\
\hline $\operatorname{SOM}(\%)$ & 3 & 0.45 & 0.63 & 1.4 & 10 & 0.19 & 0.76 & 1.1 & 4 & 0.46 & 0.62 & 1.4 \\
\hline tot C (\%) & & 0.36 & 0.29 & 1.3 & 04 & 0.35 & 0.30 & 1.2 & & 0.41 & 0.28 & 1.3 \\
\hline tot N (\%) & 4 & 0.33 & 0.031 & 1.2 & 4 & 0.44 & 0.029 & 1.3 & 4 & 0.40 & 0.030 & 1.3 \\
\hline P-AL (mg 100g $\left.{ }^{-1}\right)$ & 7 & 0.40 & 4.0 & 1.3 & 4 & 0.26 & 4.4 & 1.2 & 11 & 0.60 & 3.3 & 1.6 \\
\hline K-AL (mg 100g ${ }^{-1}$ ) & 12 & 0.02 & 5.3 & 1.0 & 3 & 0.20 & 4.8 & 1.1 & 2 & 0.16 & 4.9 & 1.1 \\
\hline Mg-AL (mg $\left.100 g^{-1}\right)$ & 8 & 0.53 & 3.5 & 1.5 & 4 & 0.38 & 4.0 & 1.3 & 9 & 0.72 & 2.7 & 1.9 \\
\hline
\end{tabular}


Table 6. NIR or VisNIR calibration models made on all reference samples at Hacksta and Sjöstorp. For validation, 25\% of the samples were randomly selected and kept out of the calibrations (31 out of 122 at Hacksta and 31 out of 125 at Sjöstorp)

\begin{tabular}{|c|c|c|c|c|c|c|c|c|}
\hline & \multicolumn{4}{|c|}{ Hacksta } & \multicolumn{4}{|c|}{ Sjöstorp } \\
\hline & $\mathrm{PC}^{1}$ & $\mathrm{R}^{2}$ & RMSEP & $\mathrm{RPD}$ & PC & $\mathrm{R}^{2}$ & RMSEP & RPD \\
\hline Clay (\%) & 5 & 0.75 & 3.6 & 2.3 & 7 & 0.95 & 2.7 & 3.7 \\
\hline Silt (\%) & 9 & 0.73 & 3.4 & 1.8 & 11 & 0.63 & 2.8 & 1.5 \\
\hline Sand (\%) & 5 & 0.93 & 2.5 & 3.4 & 10 & 0.91 & 3.8 & 3.3 \\
\hline $\mathrm{pH}$ & 8 & 0.65 & 0.10 & 1.6 & 13 & 0.85 & 0.15 & 2.8 \\
\hline $\operatorname{SOM}(\%)$ & 7 & 0.94 & 0.42 & 3.7 & 13 & 0.86 & 0.40 & 2.7 \\
\hline tot $\mathrm{C}(\%)$ & 4 & 0.89 & 0.16 & 3.4 & 08 & 0.92 & 0.17 & 2.9 \\
\hline tot $\mathrm{N}(\%)$ & 5 & 0.85 & 0.024 & 2.7 & 11 & 0.82 & 0.016 & 2.7 \\
\hline P-AL (mg $\left.100 g^{-1}\right)$ & 7 & 0.48 & 3.3 & 1.7 & 9 & 0.78 & 3.0 & 1.9 \\
\hline K-AL (mg 100g ${ }^{-1}$ ) & 7 & 0.87 & 1.9 & 2.8 & 4 & 0.68 & 2.8 & 2.0 \\
\hline Mg-AL (mg 100g $\left.{ }^{-1}\right)$ & 6 & 0.83 & 5.8 & 2.3 & 7 & 0.90 & 2.6 & 2.5 \\
\hline
\end{tabular}

${ }^{1}$ Number of PLS components used in the model. $\mathrm{n}$ is models using NIR measurements, $\mathrm{v}$ is models using VisNIR measurements

\section{Discussion}

\section{Texture}

The low RMSEP values for clay at both farms when using 25 calibration samples (3.3-4.4\%) (Table 5) were well in line with a number of other studies, often using substantially larger calibration sets (Chang et al., 2001; Moron and Cozzolino, 2003; Sørensen and Dalsgaard, 2005; Wetterlind et al., 2008a). Taking the variation in clay content into account, the RPD values (1.9-2.1 and 2.2-2.8 at Hacksta and Sjöstorp respectively) are comparable to, or better than, values reported by others, regardless of scale (Malley et al., 2000; Chang et al., 2001; Viscarra Rossel et al., 2006; Waiser et al., 2007). As is evident in the comparison with the predictions for clay content by calibration models using $75 \%$ of the reference samples (Table 6 ), the inclusion of more than 25 samples in the calibration was able to increase the prediction performance even more. RMSEP values of less than $3 \%$ as for Sjöstorp using $75 \%$ of all reference samples (2.7\%) have only been reported in a few studies (Sørensen and Dalsgaard, 2005; McCarty and Reeves, 2006; van Vuuren et al., 2006; Viscarra Rossel et al., 2006) and must be close to the limit of what is possible considering errors in sampling and the reference method. However, 25 calibration samples were sufficient for building fairly reliable calibration models for predicting clay at these two farms.

Compared with predictions for clay content, silt and sand predictions have often been proven to be more difficult. In our study, predictions for silt and sand using 25 calibration samples resulted in RMSEP values of about the same range as for clay (3.7-5.4\%). Moron and Cozzolino (2003) and Sørensen and Dalsgaard (2005) presented similar results in nation-wide studies in Uruguay and Denmark, respectively, while Viscarra Rossel et al. (2006) reported RMSE values of $2.35 \%$ for silt $\left(\mathrm{r}^{2}=0.41\right)$ and $3.30 \%$ for sand $\left(\mathrm{r}^{2}=0.59\right)$ at a 17.5 ha field in New South Wales, Australia. Others have reported SEP and RMSECV values between9.8 and $13.2 \%$ for silt and $11.9-17.6 \%$ for sand (Malley et al., 2000; Chang et al., 2001; Islam et al., 2003).

As can be seen in Tables 5 and 6, the calibration models for silt were not as good as those for sand at either farm, despite the equally low RMSEP values, especially for Sjöstorp. The fact that silt was not measured directly but rather as a difference might be part of the explanation for this, as errors in the reference methods are added. It could also to some extent be explained by differences in the variation. The variations in clay and sand content were similar at both farms, but the variations in silt content were slightly smaller at Hacksta and less than half the variations in clay and sand at Sjöstorp.

At Sjöstorp there was a strong negative correlation between clay and sand $\left(r^{2}=0.90\right)$ (Table 4). Since the dominant minerals in the sand fraction, quartz and feldspars, are nearly spectrally featureless (Hunt et al., 1973), whereas clay minerals show intrinsic spectral features caused by a variety of electronic and vibrational processes (Hunt, 1977), it could be suspected that more or less the same spectral features as for clay were used in the sand calibrations at Sjöstorp. This was further supported by the fact that using clay only as a predictor for sand resulted in comparable $r^{2}$ and RMSEP values with $75 \%$ of the samples included in the calibration as the corresponding vis-NIR calibration. However, the prediction for sand was better than that for clay at Hacksta. In addition, the correlation between clay and sand content was moderate $\left(r^{2}=0.53\right)$ and using clay to predict sand resulted in considerably lower $r^{2}$ value and twice as high RMSEP values compared with the corresponding vis-NIR calibration when $75 \%$ of all reference samples were included in the calibration. At Hacksta, some extra information other than that corresponding to clay content was clear- 
ly used in the NIR spectra, but these features could not be elucidated within the scope of this paper.

Using $75 \%$ of all reference samples in the calibrations improved the prediction results for both silt and sand at both farms. At Sjöstorp, the silt predictions in particular were greatly improved, with an increase in $\mathrm{r}^{2}$ from about 0 to 0.63 which is comparable to the best predictions using 25 calibration samples at Hacksta. Thus, 25 calibration samples might be too few, at least for silt, at Sjöstorp.

\section{SOM and total C}

The results from calibration models using 25 calibration samples for predicting SOM and total $\mathrm{C}$ at Hacksta (Table 5) were comparable to those from earlier studies on farm- or field-scale calibrations (Udelhoven et al., 2003; McCarty and Reeves, 2006; Viscarra Rossel et al., 2006; Wetterlind et al., 2008a). However, the result at Sjöstorp was less satisfactory. Low correlations between clay content and SOM and total C indicate that they were independently calibrated and not a function of clay (Tables 3 and 4). Although the RMSEP values were reduced at both farms when using $75 \%$ of all reference samples in the calibration, the $r^{2}$ values were only slightly improved at Hacksta (Tables 5 and 6), which indicates fairly stable calibrations. At Sjöstorp, on the other hand, the $\mathrm{r}^{2}$ value increased from 0.46 at best to 0.86 . The less stable results at Sjöstorp might be explained by the fact that Sjöstorp has parts with quite low clay content. Stenberg et al. (2002) and Sørensen and Dalsgaard (2005) found that the calibrations for SOM gave better predictions for soil with high clay content. In addition, the variation in the geologically divided farm could be too complicated for the 25-sample calibrations to embrace.

\section{Total N}

At Hacksta, predictions for total $\mathrm{N}$ were equally good with 25 calibration samples as with $75 \%$ of all reference samples included in the calibration, which indicates fairly stable calibrations. However, as for SOM, RMSEP values decreased and $r^{2}$ increasedfrom 0.44 to 0.82 at Sjöstorp when $75 \%$ of all references samples were included in the calibration compared with using only 25 calibration samples. The explanation for the inferior results at Sjöstorp is probably the same as for SOM. Total N was highly correlated to SOM $\left(\mathrm{r}^{2}\right.$ about 0.80 ) at both farms and the vis-NIR predictions of $\mathrm{N}$ resulted in no improvement compared with simply using total C or SOM as the sole predictor using $75 \%$ of all reference samples $\left(\mathrm{RMSEP}=0.020 \%, \mathrm{r}^{2}=0.91\right.$ at Hacksta and RMSEP $=0.019 \%, r^{2}=0.82$ at Sjöstorp) compared with NIR (Table 6). This can be compared with findings by Fystro (2002), who reported improved predictive capacity for total $\mathrm{N}$ using vis-NIR compared with using organic $\mathrm{C}$ as the predictor, but no improvement at all using loss of ignition as the sole predictor.

\section{$\mathrm{pH}$}

The calibrations for $\mathrm{pH}$ resulted in rather good predictions at Sjöstorp, whereas the results at Hacksta were less reliable. The low RMSEP values at both farms for the calibration models using 25 samples were comparable to those of $0.14-0.33$ reported by Malley et al. (1999), Reeves et al. (1999), Viscarra Rossel et al. (2006), Mouazen et al. (2007) and Zornoza et al. (2008). The corresponding $r^{2}$ values in these studies were between 0.54 and 0.73 , which are similar to the results at Sjöstorp using 25 calibration samples. At Hacksta, however, with only half the standard deviation compared with Sjöstorp, the $r^{2}$ values were not as good. Using75\% of all reference samples resulted in more reliable predictions at Hacksta and at Sjöstorp $r^{2}$ values were as high as 0.85 at best, which is in line with the better results reported previously (Dunn et al., 2002; Moron and Cozzolino, 2002; He et al., 2007) $\left(\mathrm{r}^{2}=0.80,0.91\right.$ and 0.86; RMSE=0.32, 0.09 and 0.26 respectively). The better predictions at Sjöstorp might be explained by the fact that the $\mathrm{pH}$ was somewhat correlated to clay content, which was not the case at Hacksta, or to carbonate suspected to be present mainly in most clayey areas. Both clay and carbonate promote a better buffering capacity of soil and could explain $\mathrm{pH}$ variations at the farm scale.

AL-extractable plant nutrients Farm-scale calibration models for predictions of $\mathrm{P}-, \mathrm{K}-$ and $\mathrm{Mg}-\mathrm{AL}$ appear to be feasible with a sufficient number of calibration samples. Using only 25 samples in the calibrations resulted in some cases in RPD values around 2, but mostly in less reliable results (Table 5), whereas using $75 \%$ of the reference samples in the calibrations resulted in RPD values between 1.7 and 2.8. It is difficult to compare the results for $\mathrm{P}-, \mathrm{K}-$, and $\mathrm{Mg}-\mathrm{AL}$ content with those of other studies in terms of RMSEP values due to a variety of different analytical methods resulting in the retrieval of different portions of the nutrient in question. However, RPD values of around 2 have been reported in several studies for different types of analytical methods for all the nutrients included in this study (Malley et al., 1999; Chang et al., 2001; Dunn et al., 2002; Islam et al., 2003; van Groenigen et al., 2003; van Vuuren et al., 2006; Zornoza et al., 2008). Swedish fertilisation recommendations for $\mathrm{P}$ and $\mathrm{K}$ are based on classification of the K-AL and P-AL values into five classes, with the recommendations aiming to slowly move towards the middle class. In terms of RMSEP values, using 25 samples in the calibration for predictions of K-AL at Hacksta resulted in an RMSEP value of about $3 \mathrm{mg} 100 \mathrm{~g}^{-1}$. The practical consequence of the validation is that the predictions never fail by more than one class (confidence interval of 95\%). At, Sjöstorp, $75 \%$ of all reference samples were needed to decrease the RMSEP value to $2.8 \mathrm{mg} 100 \mathrm{~g}^{-1}$ 

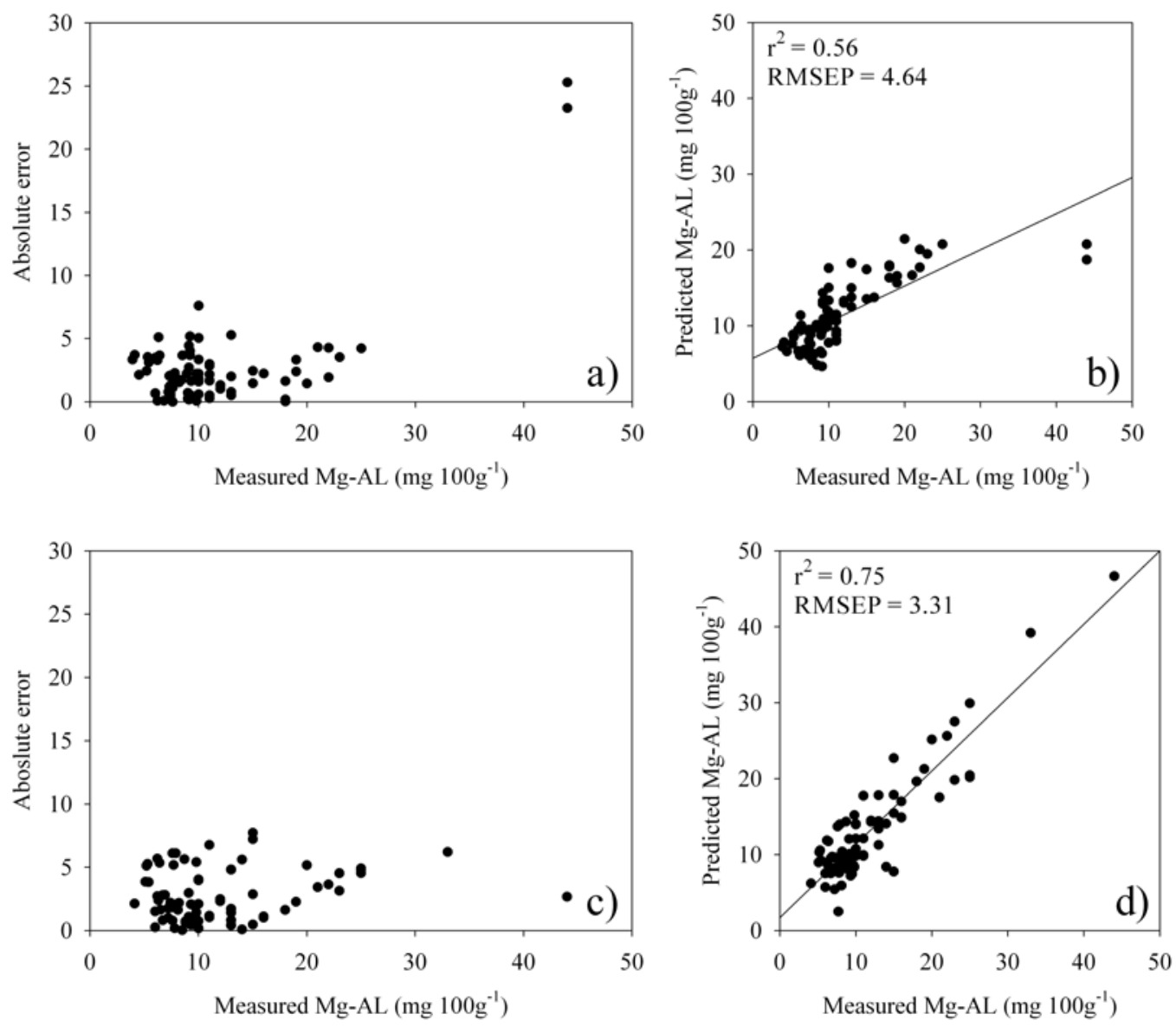

Fig. 3. Absolute error (square root (predicted-measured) ${ }^{2}$ ) in relation to measured Mg-AL for calibration models using the calibration set a) $\mathrm{SAT}_{\mathrm{SAT}}$ and c) $\mathrm{REG}_{\mathrm{NIR}}$, as well as predicted versus measured Mg-AL for calibration models using the calibration set b) SAT $_{\mathrm{SAT}}$ and d) REG $\mathrm{RIR}_{\text {. }}$

could be an artefact of the way validation samples were selected in this study. $\mathrm{g}^{-1}$. For predictions of $\mathrm{P}$ $\mathrm{AL}$, an RMSEP value of $3 \mathrm{mg} 100 \mathrm{~g}^{-1}$ means on average failure by at most one class, but with a $95 \%$ confidence interval by up to two classes if the predictions are in the lowest classes. This error corresponds to $15 \mathrm{kgP} \mathrm{ha}{ }^{-1}$ in fertilisation recommendations for cereals. With one exception, RMSEP values close to 3 $\mathrm{mg} 100 \mathrm{~g}^{-1}$ were only reached using $75 \%$ of all reference samples in the calibration at both farms. For comparison, the reported laboratory uncertainty was $\pm 20 \%$ of reading values.

One possible explanation for the good results for predictions of Mg-AL could be correlations to texture. At Sjöstorp, Mg-AL was strongly correlated to clay (Table 4), and clay content alone could predict Mg-AL with $r^{2}=0.67$ and RMSEP $=3.8$ with the same $75 \%$ of the reference samples in the calibration. At Hacksta, Mg-AL was negatively correlated to sand (Table 3) and sand content predicted $\mathrm{Mg}-\mathrm{AL}$ with $\mathrm{r}^{2}=0.50$ and
RMSEP=9.6. Similarly to Sjöstorp, this could be part of the explanation for the good calibrations, but only to some extent. Obviously there are features in the NIR spectra related to AL-extractable nutrients that are not related to texture.

\section{Distribution of calibration samples}

At Hacksta, the importance of including the total variation within the calibration samples to obtain good predictions was, at Hacksta, most evident for $\mathrm{REG}_{\mathrm{NIR}}$ and $\mathrm{EC}_{\mathrm{NIR}}$ compared with $\mathrm{REG}_{\mathrm{REG}}$ and $\mathrm{EC}_{\mathrm{EC}}$ when predicting SOM and total C. This correlation could also be seen at Sjöstorp for $\mathrm{SAT}_{\mathrm{SAT}}$ and $\mathrm{EC}_{\mathrm{EC}}$ compared with $\mathrm{SAT}_{\mathrm{NIR}}$ and $\mathrm{EC}_{\mathrm{NIR}}$ when predicting $\mathrm{Mg}-$ AL. However, when examining all calibrations, this explanation for better prediction results was not fully consistent. One of the reasons for this could be that the validation samples did not always include as much of the variation as was required, which to some extent 
could be an artefact of the way validation samples were selected in this study.

As the predicted samples exceeded the range of the calibration samples the absolute error often increased, as illustrated by Mg-AL at Sjöstorp (Fig. 3). Excluding the samples that exceeded the range of the calibration samples, leaving only the samples within the calibration set range for validation, resulted in reduced RMSEP values and higher $r^{2}$ values. These predictions were often better than the predictions on all validation samples made by calibration models that included more of the total data range in the calibration set. Predicting the reduced validation set with these models often did not result in much better prediction statistics, although even with these calibrations sometimes gave rise to larger prediction errors for the most extreme samples. This illustrates a trade-off between getting the best possible predictions for the majority of the samples and managing to sufficiently well predict the extremes. It could also be seen as an indication that 25 samples might be too few in some situations, since concentrating them to a shorter range improved the results.

At Sjöstorp, $\mathrm{SAT}_{\mathrm{SAT}}$ failed to include the whole range in several soil properties compared with all reference samples (Table 2). In many of these cases, the majority of the extreme values were found close to the borderline between the clay till and the sandy till in one of the fields. At the time of the satellite image recording, all fields had bare soil or were only sparsely covered by vegetation (young crops) except for this field, where a denser grass ley was growing. This could have led to mistargeting of some samples due to a variation not only reflecting a variation in soil parameters. A better way would have been to combine satellite images from different times so that all fields were in the same bare soil condition, since the time of collection of the image is of less importance in this case. Overall, obtaining suitable satellite images is one of the problems in using the SAT strategy.

\section{Concluding remarks}

Using only 25 calibration samples resulted in good predictions for clay at both farms. Sand, SOM, total C and total $\mathrm{N}$ were well predicted at Hacksta but 25 samples proved to be too few at the geologically divided farm Sjöstorp. For predicting $\mathrm{pH}$ and $\mathrm{P}-, \mathrm{K}-$, and $\mathrm{Mg}-\mathrm{AL}$, more than 25 calibration samples were needed at both farms, although with a sufficient number of calibration samples, these parameters also showed potential for building useful vis-NIR calibrations. However, predictions for silt content were less reliable and the small number of calibration samples did not seem to be the only limiting factor in this case.
There were no large differences in prediction results between the different strategies for selecting calibration samples in this study and most of the strategies managed to cover the important variation in the soil parameters compared with all reference samples. However, 25 calibration samples could be too few, as indicated in some of the soil parameters.

With this in mind the results presented in this study demonstrate the potential for carrying out costeffective farm soil mapping based on NIR, the potential being largest for clay, sand, SOM and total C content.

\section{Acknowledgements}

We wish to thank Jarl Ryberg and Göran Olsson for allowing us to use their fields and the Swedish Farmers' Foundation for Agricultural Research (SLF) and the Savings Bank Foundation in Skaraborg and Lidköping for funding the work. We also want to thank Ingemar Henningsson, Anita Dellsén, Lisbet Norberg, Jan-Olov Gustavsson and Kristina Gustavsson for their important help with the extensive soil sampling and Anna Nyberg for her help with the NIR measurements.

\section{References}

Ben-Dor, E. and Banin, A., 1995a. Near-Infrared Analysis (Nira) as a Method to Simultaneously Evaluate Spectral Featureless Constituents in Soils. Soil Science, 159(4): 259-270.

Ben-Dor, E. and Banin, A., 1995b. Near-Infrared Analysis as a Rapid Method to Simultaneously Evaluate Several Soil Properties. Soil Science Society of America Journal, 59(2): 364-372.

Bogrekci, I. and Lee, W.S., 2005. Spectral soil signatures and sensing phosphorus. Biosystems Engineering, 92(4): 527-533.

Chang, C.W., Laird, D.A., Mausbach, M.J. and Hurburgh, C.R., 2001. Near-infrared reflectance spectroscopy-principal components regression analyses of soil properties. Soil Science Society of America Journal, 65(2): 480-490.

Dalal, R.C., and Henry, R.J., 1986. Simultaneous Determination of Moisture, Organic Carbon, and Total Nitrogen by Near Infrared Reflectance Spectrophotometry. Soil Science Society of America Journal, 50: 120-123.

Daniel, K.W., Tripathi, X.K. and Honda, K., 2003. Artificial neural network analysis of laboratory and in situ spectra for the estimation of macronutrients in soils of Lop Buri (Thailand). Australian Journal of Soil Research, 41(1): 47-59.

Delin, S. and Söderström, M., 2003. Performance of soil electrical conductivity and different methods for mapping soil data from a small dataset. Acta Agriculturae Scandinavica Section B-Soil and Plant Science, 52(4): 127-135.

Dunn, B.W., Beecher, H.G., Batten, G.D. and Ciavarella, S., 2002. The potential of near-infrared 
reflectance spectroscopy for soil analysis - a case study from the Riverine Plain of south- eastern Australia. Australian Journal of Experimental Agriculture, 42(5): 607-614.

Egnér, H., Riehm, H. and Domingo, W.R., 1960. Untersuchungen über die chemische Bodenanalyse als Grundlage für die Beurteilung des Nährstoffzustandes der Böden. II. Chemische Extraktionsmethoden zur Phosphor- und Kaliumbestimmung (Investigations on soil chemical analysis as a basis of the evaluation of plant nutrient status of soils II. Chemical extraction methods for phosphorous and potassium determination). The annals of Royal agricultural college of Sweden(26): 199-215 (in German).

Ekström, G., 1927. Klassifikation av Svenska Åkerjordar (Classification of Swedish arable soils). 345 (Årsbok 20), Sveriges Geologiska Undersökning, Ser C. No. 345 (Årsbok 20), 161 pp.

Fystro, G., 2002. The prediction of $\mathrm{C}$ and N content and their potential mineralisation in heterogeneous soil samples using Vis-NIR spectroscopy and comparative methods. Plant and Soil, 246(2): 139-149.

Gee, G.W. and Bauder, J.W., 1986. Particle-size analysis. In: A. Klute (Editor), Physical and mineralogical methods. Agronomy series. Soil Science Society of America, Madison, pp. 383-411.

He, Y., Huang, M., Garcia, A., Hernandez, A. and Song, H., 2007. Prediction of soil macronutrients content using near-infrared spectroscopy. Computers and Electronics in Agriculture, 58(2): 144153.

Hunt, G.R., 1977. Spectral signatures of particulate minerals in the visible and near infrared. Geophysics, 42(3): 501-513.

Hunt, G.R., Salisbury, J.W. and Lenhoff, C.J., 1973. Visible and near infrared spectra of minerals and rocks: VI. Additional silicates. Modern Geology, 4: 85-106.

Islam, K., Singh, B. and McBratney, A., 2003. Simultaneous estimation of several soil properties by ultra-violet, visible, and near-infrared reflectance spectroscopy. Australian Journal of Soil Research, 41(6): 1101-1114

Maleki, M.R. van Holm, L., Ramon, H., Merckx, R., De Baerdemaeker, J. and Mouazen, A.M., 2006. Phosphorus sensing for fresh soils using visible and near infrared spectroscopy. Biosystems Engineering, 95(3): 425-436.

Malley, D.F., Martin, P.D., McClintock, L.M., Yesmin, L., Eilers, R.G. \& Haluschak, P., 2000. Feasibility of analysing archived Canadian prairie agricultural soils by near infrared reflectance spectroscopy. In: A.M.C. Davies and R. Giangiacomo (Editors), Near Infrared Spectroscopy: Proceedings of the 9th International Conference. NIR Publications, Chichester, UK, pp. 579-585.

Malley, D.F., Yesmin, L., Wray, D. and Edwards, S., 1999. Application of near-infrared spectroscopy in analysis of soil mineral nutrients. Communications in Soil Science and Plant Analysis, 30(7-8): 9991012.
Martens, H. and Naes, T., 1989. Multivariate calibration. John Wiley \& Sons, Chichester, UK, 419 pp.

McCarty, G.W. and Reeves, J.B., 2006. Comparison of near infrared and mid infrared diffuse reflectance spectroscopy for field-scale measurement of soil fertility parameters. Soil Science, 171(2): 94-102.

Moron, A. and Cozzolino, D., 2002. Application of near infrared reflectance spectroscopy for the analysis of organic $\mathrm{C}$, total $\mathrm{N}$ and $\mathrm{pH}$ in soils of Uruguay. Journal of near Infrared Spectroscopy, 10(3): 215-221.

Moron, A. and Cozzolino, D., 2003. Exploring the use of near infrared reflectance spectroscopy to study physical properties and microelements in soils. Journal of near Infrared Spectroscopy, 11(2): 145154.

Morra, M.J., Hall, M.H. and Freeborn, L.L., 1991. Carbon and nitrogen analysis of soil fractions using near-infrared reflectance spectroscopy. Soil Science Society of America Journal, 55: 288-291.

Mouazen, A.M., Maleki, M.R., De Baerdemaeker, J. and Ramon, H., 2007. On-line measurement of some selected soil properties using a VIS-NIR sensor. Soil \& Tillage Research, 93(1): 13-27.

Möller, H., 1985. Beskriving till jordartskartan Enköping SV. Deskription to the quaternary map Enköping SV, Sveriges Geologiska Undersökning, Uppsala.

Olsson, D. and Söderström, M. 2003. An automated method to locate optimal soil sampling sites using ancillary data. In: Program book of the joint conference of ECPA - ECPLF, Berlin, edited by A. Werner and A. Jarfe. Poster at the 4th European Conference on Precision Agriculture, Wageningen Academic Publishers, The Netherlands, pp. 649. (www.agrovast.se/precision/soilmap)

Reeves, J.B., McCarty, G.W. and Meisinger, J.J., 1999. Near infrared reflectance spectroscopy for the analysis of agricultural soils. Journal of near Infrared Spectroscopy, 7(3): 179-193.

Savitzky, A. and Golay, M., 1964. Smoothing and differentiation of data by simplified least squares procedures. Analytical chemistry, 36: 1627-1639.

Shepherd, K.D. and Walsh, M.G., 2002. Development of reflectance spectral libraries for characterization of soil properties. Soil Sci Soc Amer J, 66: 988998.

Stenberg, B., Jonsson, A. and Börjesson, T., 2002. Near infrared technology for soil analysis with implications for precision agriculture. In: A. Davies and R. Cho (Editors), Near Infrared Spectroscopy: Proceedings of the 10th International Conference. NIR Publications, Chichester, UK, Kyongju S. Korea, pp. 279-284.

Stenberg, B., Nordkvist, E. and Salomonsson, L., 1995. Use of near infrared reflectance spectra of soils for objective selection of samples. Soil Science, 159(2): 109-114.

Sudduth, K.A. and Hummel, J.W., 1991. Evaluation of reflectance methods for soil organic matter sensing. Transactions of the ASAE, 34(4): 1900-1909. 
Sørensen, L.K. and Dalsgaard, S., 2005. Determination of clay and other soil properties by near infrared spectroscopy. Soil Science Society of America Journal, 69(1): 159-167.

Udelhoven, T., Emmerling, C. and Jarmer, T., 2003. Quantitative analysis of soil chemical properties with diffuse reflectance spectrometry and partial least-square regression: A feasibility study. Plant and Soil, 251(2): 319-329.

Waiser, T.H., Morgan, C.L.S., Brown, D.J. and Hallmark, C.T., 2007. In situ characterization of soil clay content with visible near-infrared diffuse reflectance spectroscopy. Soil Science Society of America Journal, 71(2): 389-396.

van Groenigen, J.W., Mutters, C.S., Horwath, W.R. and van Kessel, C., 2003. NIR and DRIFT-MIR spectrometry of soils for predicting soil and crop parameters in a flooded field. Plant and Soil, 250(1): 155-165.

van Vuuren, J.A.J., Meyer, J.H. and Claassens, A.S., 2006. Potential use of near infrared reflectance monitoring in precision agriculture. Communications in Soil Science and Plant Analysis, 37(1520): 2171-2184.

Wetterlind, J., Stenberg, B. and Jonsson, A., 2008a. Near infrared reflectance spectroscopy compared with soil clay and organic matter content for es- timating within-field variation in $\mathrm{N}$ uptake in cereals. Plant and Soil, 302: 317-327.

Wetterlind, J., Stenberg, B. and Söderström, M., 2008b. The use of near infrared (NIR) spectroscopy to improve soil mapping at the farm scale. Precision Agriculture, 9(1-2): 57-69.

Williams, P.C., 1987. Variables Affecting NearInfrared Reflectance Spectroscopic Analysis. In: P. Williams and K. Norris (Editors), NearInfrared Technology in the Agricultural and Food Industries. Am. Assoc. Cereal Chem., St. Paul, MN, pp. 143-167.

Viscarra Rossel, R.A., Walvoort, D.J.J., McBratney, A.B., Janik, L.J. and Skjemstad, J.O., 2006. Visible, near infrared, mid infrared or combined diffuse reflectance spectroscopy for simultaneous assessment of various soil properties. Geoderma, 131(1-2): 59-75.

Zornoza, R. Guerrero, C., Mataix-Solera, J., Scow, K.M., Arcenegui, V. and Mataix-Beneyto, J.,, 2008. Near infrared spectroscopy for determination of various physical, chemical and biochemical properties in Mediterranean soils. Soil Biology \& Biochemistry, 40(7): 1923-1930. 